\title{
Diagnosis of Inherited Platelet Disorders on a Blood Smear
}

\author{
Carlo Zaninetti ${ }^{1,2,3}$ and Andreas Greinacher ${ }^{1, *}$ \\ 1 Institut für Immunologie und Transfusionsmedizin, Universitätsmedizin Greifswald, 17489 Greifswald, \\ Germany; carlo.zaninetti@uni-greifswald.de \\ 2 University of Pavia, and IRCCS Policlinico San Matteo Foundation, 27100 Pavia, Italy \\ 3 PhD Program of Experimental Medicine, University of Pavia, 27100 Pavia, Italy \\ * Correspondence: andreas.greinacher@med.uni-greifswald.de; Tel.: +49-3834-865482; Fax: +49-3834-865489
}

Received: 19 January 2020; Accepted: 12 February 2020; Published: 17 February 2020

\begin{abstract}
Inherited platelet disorders (IPDs) are rare diseases featured by low platelet count and defective platelet function. Patients have variable bleeding diathesis and sometimes additional features that can be congenital or acquired. Identification of an IPD is desirable to avoid misdiagnosis of immune thrombocytopenia and the use of improper treatments. Diagnostic tools include platelet function studies and genetic testing. The latter can be challenging as the correlation of its outcomes with phenotype is not easy. The immune-morphological evaluation of blood smears (by light- and immunofluorescence microscopy) represents a reliable method to phenotype subjects with suspected IPD. It is relatively cheap, not excessively time-consuming and applicable to shipped samples. In some forms, it can provide a diagnosis by itself, as for MYH9-RD, or in addition to other first-line tests as aggregometry or flow cytometry. In regard to genetic testing, it can guide specific sequencing. Since only minimal amounts of blood are needed for the preparation of blood smears, it can be used to characterize thrombocytopenia in pediatric patients and even newborns further. In principle, it is based on visualizing alterations in the distribution of proteins, which result from specific genetic mutations by using monoclonal antibodies. It can be applied to identify deficiencies in membrane proteins, disturbed distribution of cytoskeletal proteins, and alpha as well as delta granules. On the other hand, mutations associated with impaired signal transduction are difficult to identify by immunofluorescence of blood smears. This review summarizes technical aspects and the main diagnostic patterns achievable by this method.
\end{abstract}

Keywords: inherited platelet disorders; hereditary thrombocytopenias; blood smear; immunofluorescence; bleeding tendency

\section{Introduction}

\subsection{Inherited Platelet Disorders}

Inherited platelet disorders (IPDs) are a group of rare diseases characterized by reduced platelet numbers and impaired platelet function, causing variable bleeding diathesis. They can affect only platelets, present with other congenital features (syndromic forms), or confer the risk to develop over time additional manifestations such as nephropathy or hematological malignancies (predisposing forms) [1].

The landscape of IPDs comprises, in early 2020, more than 30 disorders and 50 genes. Particularly with the development of high-throughput sequencing tools, the list of IPDs has become enriched rather rapidly [2-8].

In IPDs, at least one of the three main phases of platelet biogenesis is impaired [9]. The genetic defect can alter the differentiation of hematopoietic stem cells into megakaryocytes (Mks), as in 
congenital amegakaryocytic thrombocytopenia (CAMT), due to biallelic mutations in the gene coding of the receptor for thrombopoietin (TPO) MPL causing major deficiency or even absence of Mks in the bone marrow [10]. Mutations in transcriptional regulators, such as RUNX1 or ETV6, hit Mk maturation and perturb hematopoietic precursors leading to thrombocytopenia, impaired platelet function, and increased risk of clonal hematopoiesis [11-14]. Alterations in cytoskeletal proteins, such as non-muscular myosin IIA, $\beta 1$-tubulin, alpha $(\alpha)$ 1-actinin or filamin A, target the phase of platelet formation and release into blood vessels. In these forms, platelets are typically reduced in number and increased in size [15-18]. Finally, some IPDs induce thrombocytopenia by reducing the platelet life span, such as changes in glycosylation due to a mutated glucosamine (UDP- $N$-acetyl)-2-epimerase/ $N$-acetylmannosamine kinase (GNE) gene; or impaired function of the ubiquitination, proteasome system in ANKRD26-related thrombocytopenia (ANKRD26-RT) [19-22].

\subsection{Bleeding Symptoms do not Allow Specific Diagnosis of an IPD}

From a clinical point of view, IPDs are characterized by highly variable bleeding tendency. The hemorrhagic history of patients with platelet function defects is significantly more severe than that of patients with thrombocytopenia only, who sometimes present with no bleeding at all. Most affected individuals do not have a spontaneous hemorrhage, but may develop bleeding complications in case of hemostatic challenges such as traumas or surgery. When present, spontaneous bleedings are prevalently muco-cutaneous (e.g., easy bruising, epistaxis, gum bleeding, menorrhagia, gastrointestinal bleeding) and rarely serious [23]. When a hemorrhagic phenotype is overt, the kind of symptoms may help to differentiate "IPD-" from "non-IPD-bleeding-subjects" (e.g., having coagulopathies). In contrast, this criterion is fairly useless in distinguishing among diverse IPDs as symptomatic patients commonly share prevalently mucocutaneous hemorrhages [23].

Apart from a few exceptions, the platelet count in IPDs is stable during life, unless additional causes for thrombocytopenia are acquired. In the absence of compromised platelet function, the severity of bleeding tendency primarily depends on the platelet count [1]. Lifelong bleeding history, female sex, and some types of interventions (e.g., cardiovascular or urological procedures associate with a higher risk of hemorrhagic complications) predict the individual risk of bleeding at surgery [24].

\subsection{Non-Platelet Features Clinically Characterize some IPDs}

Some IPDs present with congenital defects depicting peculiar syndromic pictures. For instance, skeletal defects lead to pathognomonic deformations in Thrombocytopenia-absent radius syndrome (TAR) or Radioulnar synostosis with amegakaryocytic thrombocytopenia (RUSAT) $[25,26]$. Eczema and mild-to-severe immunodeficiency associate with Wiskott-Aldrich syndrome (WAS) and X-linked thrombocytopenia (XLT), respectively $[27,28]$. Red blood cell (RBC) thalassemic-like abnormalities are typically found in GATA1-related thrombocytopenia (GATA1-RT) [29], while Stormorken- and York platelet syndrome share the finding of congenital myopathy $[30,31]$.

"Predisposing IPDs" make patients prone to develop, during life, additional manifestations hitting different systems. With regard to the most prevalent MYH9-related disease (MYH9-RD), the affected subjects can manifest sensorineural deafness, nephropathy, juvenile cataracts, and elevation of liver enzymes. The individual risk of such features depends on the location of the mutation, which differently affects protein function [32]. A risk for deafness is also present in patients with macrothrombocytopenia due to DIAPH1 mutations [33].

Much more relevant for prognosis, all patients with CAMT develop critical bone-marrow aplasia during infancy [34]. A similar evolution can affect the proportion of patients with RUSAT [26]. A possible progression to hematological malignancies has been reported in three forms of autosomal dominant (AD) IPDs with congenital thrombocytopenia with normal-size platelets [35,36]. The proportion of patients developing myelogenous or lymphoblastic leukemia, or myelodysplastic syndrome, ranges from less than $10 \%$ in ANKRD26-RT to about 25\% and 33\% in ETV6-related thrombocytopenia (ETV6-RT) and in Familial platelet disorder with propensity to acute myelogenous leukemia 
(FDP/AML), respectively [12,13,37-42]. A potential onset of juvenile myelofibrosis, splenomegaly, and osteoporosis has been reported in subjects with mutations in tyrosine kinase SRC (SRC-related thrombocytopenia) [43].

\subsection{Treatment of IPDs is Usually Symptomatic}

Hematopoietic stem cell transplantation (HSCT) is indicated for CAMT, WAS, severe phenotypes, or poor prognosis IPDs; otherwise, treatment is mostly symptomatic [44,45]. Spontaneous and provoked bleedings can be prevented by simple behavioral norms such as avoiding antiplatelet drugs and contact sports, providing regular dental care, and reducing menorrhagia with hormonal therapy. For the therapeutic management of moderate hemorrhage, anti-fibrinolytic agents and desmopressin are effective options. Only in the case of severe bleeding, platelet concentrates, or pro-hemostatic compounds, such as recombinant activated factor VII (rFVIIa) are indicated [46-48]. In preparation for surgical procedures, the increase of platelet number and/or the restoring of platelet function can be required. Especially in IPDs with defective platelet function, anti-hemorrhagic prophylaxis is associated with a significant reduction of bleeding frequency [24]. The threshold platelet levels considered safe to undergo invasive procedures vary according to the kind of hemostatic challenge (e.g., childbirth, or major surgery), and the severity of platelet dysfunction. In the case of a major hemostatic challenge in a patient with major platelet dysfunction, platelet transfusion is recommended independently of the platelet count target [49-51]. However, especially in Glanzmann's thrombasthenia (GT), platelet transfusion should be restricted to situations in which other treatments fail to reduce the risk of alloimmunization of patients against the glycoprotein lacking on their own platelets. To transiently increase the platelet count, a thrombopoietin-receptor agonist (TPO-RA) may represent an alternative to platelet concentrates in a subgroup of IPDs [52,53]. Only in WAS, splenectomy represents an option to increase platelet count. Splenectomy should not, however, be adopted in patients who are candidates for HSCT as it worsens the disease-related immunodeficiency [54]. Valid alternatives for these subjects are gene therapy, or TPO-RAs $[55,56]$. Effective strategies to cure extra-hematological features of MYH9-RD, such as renin-angiotensin pathway inhibitors to slow nephropathy progression, or cochlear implantation to overcome profound deafness, have become available during the last decade for patients at risk for these complications [57,58].

\subsection{Current Diagnostic Tools for IPDs}

IPDs are suspected when there is an unusual bleeding history and/or other phenotypic clues are present. When other affected relatives are present, or peculiar syndromic features are detectable, the diagnosis of an IPD can be made relatively easily. However, identification of the altered platelet structure is usually very challenging. On the other hand, the lack of inheritance trait does not exclude IPDs. Indeed, sporadic cases by de novo mutations or mosaicism have been reported in more than one-third of patients with MYH9-RD, one of the less rare IPDs [59].

Besides clinical evaluation, including the documentation of hemorrhagic history using a validated assessment tool, such as the ISTH Bleeding Assessment Tool (ISTH-BAT) [23,60], the first diagnostic step for IPDs requires an estimation of platelet size [61], light-transmission aggregometry (along with the evaluation of dense granule release by lumiaggregometry), and flow cytometry. Generally, only selected patients undergo, in the first instance, further sophisticated investigations like western blotting, electron microscopy, or the measurement of certain enzyme activity [62]. These platelet function assays have several shortcomings. Globally, the level of standardization of such assays is low. In addition, relatively large amounts of fresh blood are required, which makes it impossible to ship samples, and requires patients to be at the place of analysis. For aggregometry, a minimum of platelet concentration (i.e., not less than $80 \times 10^{3}$ per $\mu$ l) is required within platelet-rich plasma or whole blood for effective analysis [63-65]. This can pose a challenge when dealing with patients having moderate or severe thrombocytopenia. Additionally, the collection of large volumes of blood is not possible from neonates and young children. 
Genetic analysis has taken a big leap forward during the last ten years. The spread of next-generation sequencing (NGS) greatly contributed to the unraveling of the genetic basis of several forms of IPD, and thus immediately became a significant diagnostic tool in the field. Using a small amount of blood with minor risk of pre-analytical artifacts, it can provide patients with a highly accurate diagnosis [4-7,66-72]. As it becomes cheaper to perform, it is not inconceivable that NGS could become the standard above other diagnostic techniques. However, interpretation of genetic findings can be difficult especially in patients without a peculiar clinical picture. In fact, NGS usually detects many variants of unknown or uncertain significance, whose correlation with the patient's phenotype is unresolved, and over-interpretation is a major risk [73-77]. Data from big case series reported so far indicated that NGS is able to achieve a diagnosis in nearly 50\% of IPD patients suffering from congenital thrombocytopenia, and in nearly $25 \%$ of those with inherited platelet function disorder. Taken together, these data show that the probability of achieving a definite diagnosis by NGS is very high in selected and well-characterized individuals, but the underlying molecular cause of an IPD may still not be identified in a large number of patients.

\subsection{Main Advantages of Blood Smear Analysis}

In such a landscape, the immune-morphological analysis of platelets on the blood smear may represent a key approach in the work-up of IPDs both for feasibility and diagnostic power for the following reasons: first, it requires a low volume of blood (less than $100 \mu \mathrm{l}$ ), thus is easily collected even from newborns [78]. Secondly, samples can be shipped safely, even long distances, to reach the diagnostic reference centers. Thirdly, although requiring specialized expertise, it is relatively cheap and not excessively time-consuming. For instance, at our Institute, the overall procedure (including staining and assessing the blood smears for a large panel of markers) takes about 45 min per patient. Fourthly, the immune-morphological evaluation of blood smears allows more detailed phenotyping of the platelets [79]. The double-analysis approach (i.e., by light- and immunofluorescence-microscope, see below) can provide diagnosis by itself, as in the case of MYH9-RD, or in addition to other first-line tests such as aggregometry and flow cytometry as for GT and its variants (type 2- and type 3 GT), or for classical and monoallelic Bernard-Soulier syndrome (BSS) [80-83]. In addition, it can indicate for clinicians that the patient may have an increased risk for bleeding during interventions, as in the case of major alterations in $\alpha$ - or dense granule content (i.e., Grey Platelet Syndrome, GPS, $\alpha-, \delta-$, or $\alpha+\delta$ storage pool disease, SPD) [62,84]. By labeling a few proteins, a potential abnormality could be identified or narrowed-down to a group of IPDs featured by cytoskeleton alterations (e.g., FLNA-related thrombocytopenia, FLNA-RT [17], TUBB1-related thrombocytopenia, TUBB1-RT [85], and WAS). Likewise, it is possible to differentiate between GPS and GFI1B-related thrombocytopenia (GFI1B-RT), in the case of large and pale staining platelets in the May-Grünwald Giemsa (MGG) blood smear. Both have major deficiencies in $\alpha$-granule proteins, but only GFI1B-RT platelets express the stem cell antigen CD34 [86].

An international study that involved 3217 patients referred to four major specialized centers demonstrated that double-stained blood smear analysis was able to achieve a diagnosis of IPD (confirmed by parallel genetic testing and standard laboratory tools) in $27 \%$ of the referred subjects. This proportion was equivalent to those achieved in the major previous case series, where all the available diagnostic tools, including those requiring a larger amount of blood, were exploited [78].

\section{Technical Considerations}

\subsection{Preparation of Blood Smears}

Either capillary blood, obtained by finger-prick, or anticoagulated blood can be used for the preparation of blood smears. In the latter case, the choice of ethylenediaminetetraacetic acid (EDTA) is advisable with respect to other anticoagulants (e.g., citrate, or hirudin) since it proved to maintain superior stability of immune-morphological markers [87]. When using anticoagulated blood, slides 
should be prepared as soon as possible (within $4 \mathrm{~h}$ ) after drawing to avoid the increase of platelet size due to low calcium concentration. Since the marginal band of microtubules depolymerizes at low temperatures, leading to alteration of the discoid platelet shape, the blood should be stored at temperatures $>20^{\circ} \mathrm{C}[88]$.

The blood smear preparation is relatively simple. When correctly executed, blood films are stable for several days and can be shipped by regular mail even over long distances. The slides should be preferably prepared by skilled persons, by following a few simple recommendations. Glass slides have to be clean and fat-free. An about 3-4 $\mu \mathrm{L}$ blood drop is placed on the base-slide $1 \mathrm{~cm}$ from the edge. The spreader-slide, inclined at an angle of about 40 degrees, is then placed on the base slide, ahead of the drop, and pulled back to make contact with blood. As soon as the drop has spread out along the line of contact, the smear is obtained by rapidly moving towards the spreader-slide. The ideal length of the smear is $2 / 3$ of that of the base-slide. To form a cell-monolayer, the ideal smear has to be neither too thin nor too thick. Thickness depends on the dimension of the blood drop, the angle of the spreader-slide, and the speed of the spreading. The lateral edges and an oval-shaped tail should be visible (Figure 1). Once smeared, the slides should be immediately air-dried [89]. A You-Tube instruction on how to make the blood smears is available under the following link: https://www.youtube.com/watch?v=BbBcWp5LAXs.

Artefactual alterations of platelets or leukocytes on the smear can be induced by hemolysis due to moisture precipitation occurring during air freight when a cool glass slide comes into contact with warm, humid air. Hence, it is recommended to wrap the slides before shipment.

At least 15 to 20 slides should be collected from each patient, as typically only two colors per slide (red and green $=$ two different antibodies) are used for immunofluorescence staining.

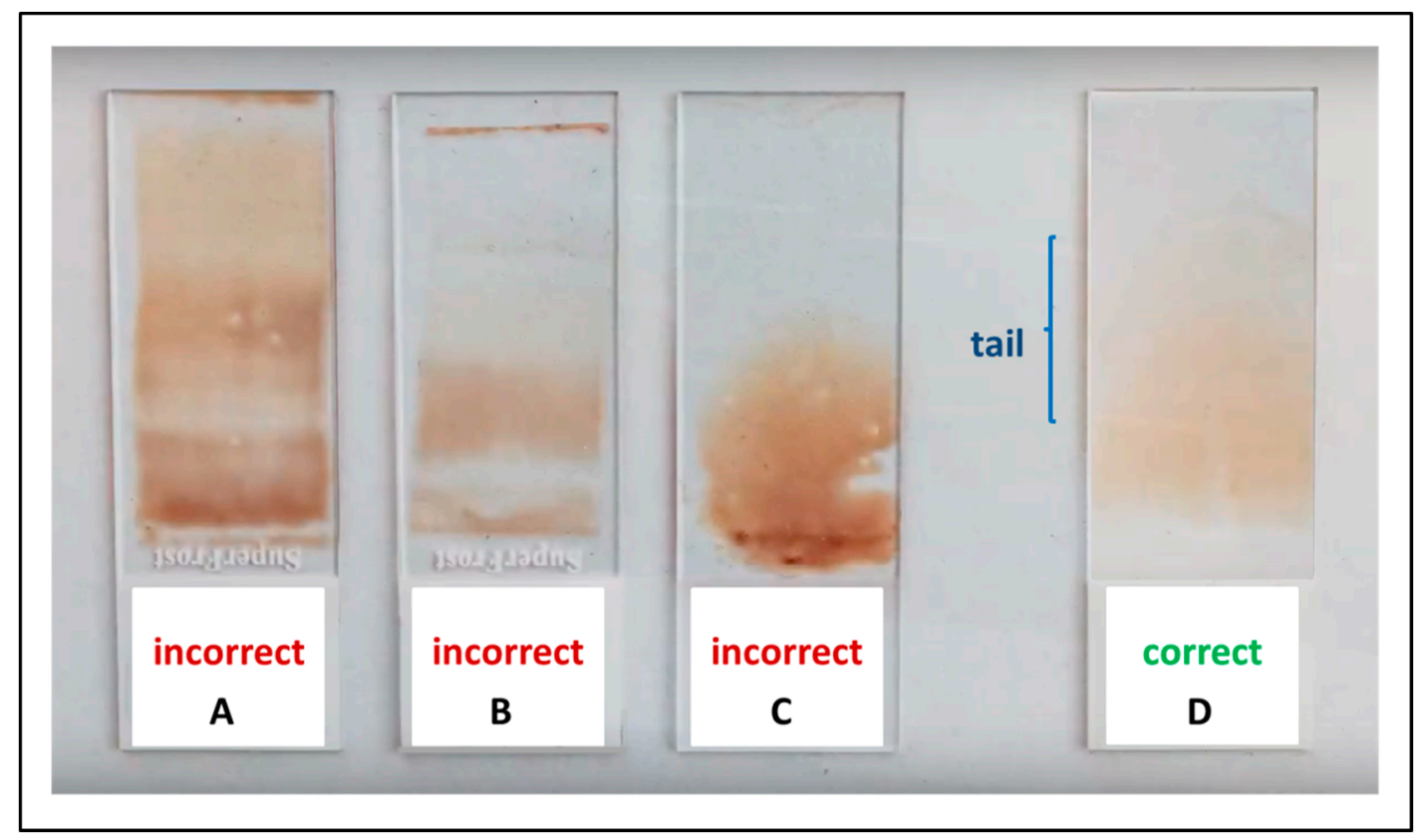

Figure 1. Blood smear preparation. (A-C) Three examples of incorrect blood smears because of excessive thickness of the blood film and the absence of the monolayer tail. (D) An ideal blood smear with evident lateral edges and a visible oval-shaped tail.

\subsection{Immunofluorescence Labelling}

Immunofluorescence staining and analysis are usually performed in specialized laboratories. Nevertheless, referring physicians should take into account that slides should ideally be fixed within three days after film preparation, and the timing of shipment has to be planned accordingly. 
Before immunofluorescence staining, slides undergo fixation using different methods according to the protocol in use in the laboratory. The main options are ice-cold acetone $\left(-20{ }^{\circ} \mathrm{C} ; 2-5 \mathrm{~min}\right.$, permeabilizing), or methanol $\left(-20^{\circ} \mathrm{C}, 1 \mathrm{~min}\right.$, permeabilizing), or $1-3 \%$ paraformaldehyde (room temperature for $10-20 \mathrm{~min}$, followed by permeabilization with $0.1-0.2 \%$ Triton X-100 for $5-10 \mathrm{~min}$ ). After fixation and permeabilization, blood smears are covered with monoclonal or polyclonal antibodies against the target proteins [78]. Fluorescence can be obtained by antibodies directly conjugated with a fluorescent dye, or by secondary antibodies labeled with fluorescent dyes that bind to primary antibodies. By staining in parallel the target protein (e.g., MYH9) and another platelet-specific marker (e.g., 31 -tubulin), easy identification of the distribution of the protein of interest can be achieved. To counterstain nuclei, Hoechst or 4' ${ }^{\prime}$, 6-diamidino-2-phenylindole (DAPI) are commonly used. It is highly advisable to always stain for two platelet structures. Otherwise, the interpretation becomes very difficult if a protein is missing. The expression pattern of the target proteins is then detected by comparison with a normal control smear stained in parallel.

\subsection{Note of Caution}

Although binding to the same protein, different monoclonal antibodies differ in their avidity and binding strength. Especially for quantitative assessment, appropriate controls and quality measures are mandatory. In addition, the absence of binding of a monoclonal antibody does not prove the absence of the protein. In the case of a polymorphism of the gene affecting only the binding site of the monoclonal antibody, the protein may be present despite the antibody, not binding.

\section{Main Diagnostic Patterns}

\subsection{Light Microscopy}

MGG- or Wright-stained blood film analysis represents the first step of the differential diagnosis of IPDs on a blood smear. First, it allows an estimate of the platelet count, which can be underestimated by automated cell counters in patients with platelet macrocytosis [90]. Second, it enables the evaluation of platelet size and platelet staining. In addition, light microscopy can identify morphological abnormalities of other blood cells, which can guide the diagnostic work-up. Conventionally, at least 100 platelets (and other blood cells) per smear should be observed.

\subsection{Platelet Size}

The assessment of the mean platelet diameter (MPD) is a key step of the differential diagnosis of IPDs. It can be achieved by an ocular micrometer or by software-assisted image analysis. A collaborative study on a large series of subjects with 19 different disorders proposed a classification of IPDs according to platelet diameter. Namely, it distinguished forms with enlarged (MPD $>3.2 \mu \mathrm{m}$ ), decreased (MPD $<2.6 \mu \mathrm{m})$, and normal $(2.6 \mu \mathrm{m}<$ MPD $<3.2 \mu \mathrm{m})$ MPD [61]. Particularly, the finding of MPD $>3.9 \mu \mathrm{m}$ (corresponding to about half the diameter of a normal red blood cell) or $<2.6 \mu \mathrm{m}$ showed good sensitivity and specificity in differentiating IPDs with giant platelets (i.e., MYH9-RD and BSS) from those with small platelets (i.e., TAR, CAMT, and WAS/XLT), respectively. An example of normal and altered platelet dimensions is shown in Figure 2, Panel I. 

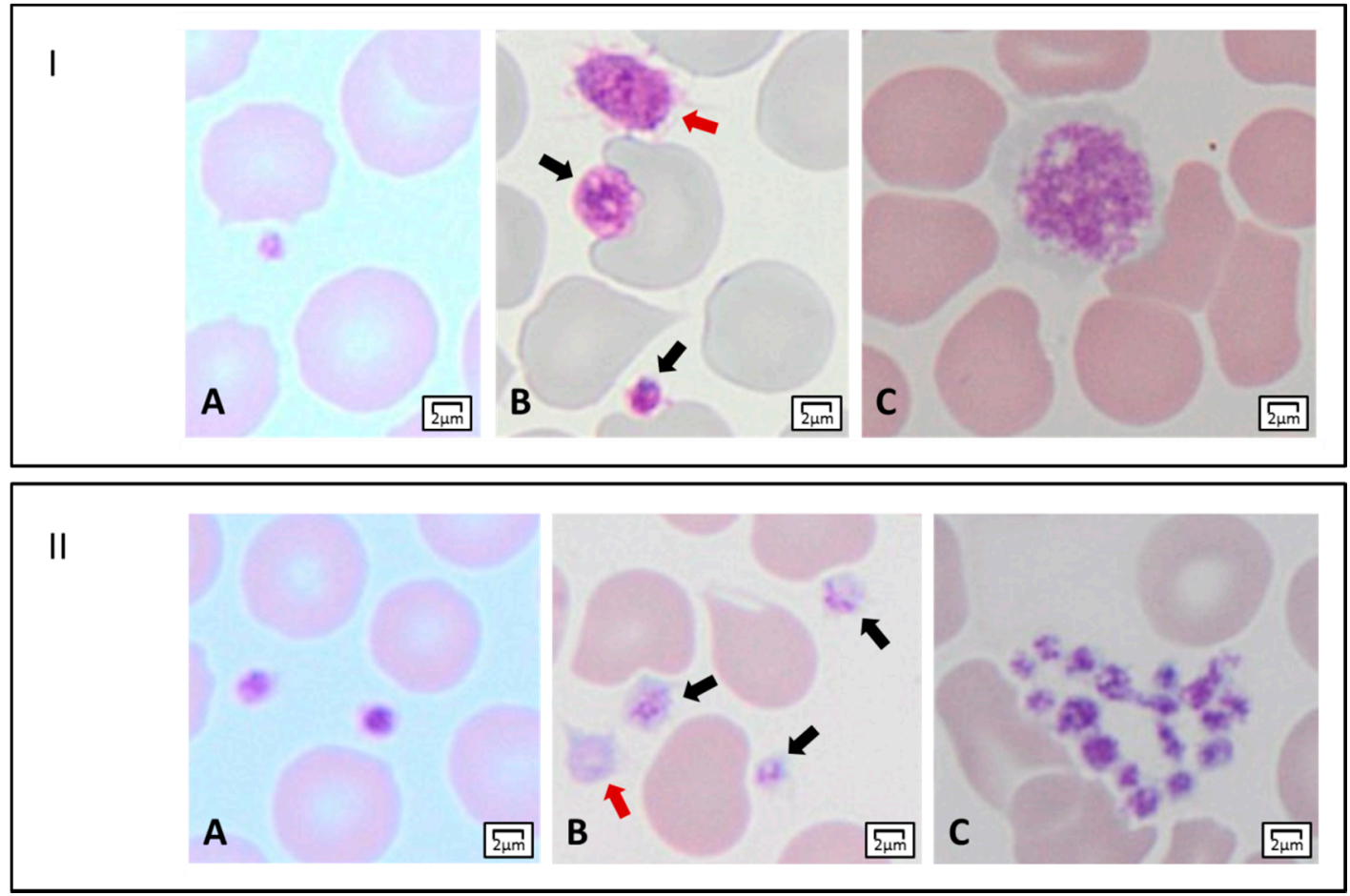

Figure 2. Light microscopy features of platelets. Panel I. Platelet dimensions. (A) A small platelet (mean platelet diameter, MPD $<2 \mu \mathrm{m}$ ). (B) Two platelets within the normal range of MPD (black arrows), and an enlarged platelet (MPD $>3.5 \mu \mathrm{m}$ ) (red arrow). (C) A giant platelet with MPD corresponding to about that of a normal red blood cell. Panel II. Platelet staining, and morphology. (A) Normal-stained platelets. (B) Platelets with reduced granular labeling (black arrows), and a gray platelet (red arrow).

(C) A platelet clump.

\subsection{Platelet Staining}

The presence of azurophilic granules (e.g., platelet $\alpha$-granules) determines the typical eosinophilic aspect of platelets. A reduction of platelet staining can suggest at least three forms of IPDs with thrombocytopenia and normal-to-enlarged platelet size. In GPS, the prototypical form of this group, $\alpha$-granules are almost completely absent, and platelets appear large and empty [84]. In GFI1B-RT or GATA1-RT, a partial reduction of granularity making platelets "pale" can be detected [91,92]. Regarding $\alpha-, \delta-$ or $\alpha+\delta$ SPD, only in the case of a severe reduction of $\alpha$-granules will platelets appear less stained by light microscopy. An example of normal and reduced platelet staining is shown in Figure 2, Panel II.

\subsection{Other Morphological Alterations of Platelets}

The presence of platelet clumps (Figure 2, Panel II), despite the best efforts to avoid platelet activation during blood-letting and preparation of blood smears, can suggest type 2B- or platelet-type von Willebrand disease (vWD) [93,94]. In the latter, platelets are often enlarged [95].

The presence of giant $\alpha$-granules can indicate Thrombocytopenia Paris-Trousseau (TCPT) [96]. Prominent vacuoles can be observed in the platelets of patients affected by GATA1-RT [97].

Note of caution: the most frequent reasons for platelet aggregates on the blood smear is the use of blood from a finger prick or the time taken between dropping the $3 \mu \mathrm{L}$ of blood onto the slide and creating the smear was too long resulting in the activation of platelets through contact with the glass surface. 


\section{Morphological Alterations of Other Blood Cells}

When dealing with large platelets, the "reader" of the blood smear should carefully look for possible basophil inclusions in neutrophils' cytoplasm, which are pathognomonic in MYH9-RD [96]. It has to be taken into account that the so-called "Döhle-like" bodies, always identifiable by immunofluorescence, are detectable only in a proportion of the affected patients by light microscopy (see below).

Among subjects with pale platelets, the finding of red blood cell (RBC) anisopoichilocytosis (i.e., cells having prominent differences in size and shape) can corroborate the suspicion of GATA1-RT [97]. The presence of erythrocytes resembling a mouth (i.e., stomatocytes) plus platelet macrocytosis can indicate sitosterolemia (STSL-RT) [98].

In regard to RBCs, microcytosis and hypochromia are often detectable in symptomatic IPD patients, independently on their specific form, because of bleeding-related iron deficiency anemia.

\subsection{Immunofluorescence Microscopy}

Immunofluorescence analysis represents the second step of the differential diagnosis of IPDs on a blood smear. Several platelet proteins, belonging to different categories (see below) can be labeled by antibodies. Based on clinical features (e.g., hereditary trait, presence of syndromic picture) or morphological aspects (e.g., enlarged or small platelets), a proper panel of antigens to be tested can be defined. Another approach is to use a standard minimum-panel for all the patients under investigation, to be probably integrated as a second step with further staining or other diagnostic tests. This latter approach allows us to gain more information and to provide a guidance answer more rapidly. Most important, it allows the blood smear reader to gain experience of how certain platelet structures are altered in various IPDs.

\subsection{Cytoskeleton Proteins}

A considerable group of IPDs are characterized by alterations in cytoskeleton proteins, reducing platelet production, and altering platelet size.

The platelet cytoskeleton often shows alterations in various IPDs associated with platelet macrocytosis as well as in acquired platelet disorders. In addition, it can be an artifact in case of platelet pre-activation or cold storage of the blood tube before preparing the smear.

Abnormal distribution of the $\mathrm{MYH9}$ coded protein non-muscular myosin IIA heavy chain in the cytoplasm of neutrophils drives the diagnosis of MYH9-RD with high sensitivity and specificity [96]. The pathognomonic inclusions, not always detectable in the MGG-stained blood smear, are usually evident in immunofluorescence (Figure 3, Panel I). At least two main patterns have been described. The one is typical for mutations involving the tail domain of non-muscular myosin IIA and consists of one-to-three large $(2-5 \mu \mathrm{m})$ aggregates per cell together with further small aggregates. Conversely, mutations involving the head domain of the protein produce several smaller $(<0.5 \mu \mathrm{m})$ aggregates. Not all leukocytes may express these inclusion bodies, especially in the case of a genetic mosaic of the patient.

Double labeling for cytoskeleton markers $\beta 1$-tubulin and filamin A enables to recognize patterns suggestive for two forms of IPD with large, normal-stained platelets: TUBB1-RT and FLNA-RT [17,85]. TUBB1-RT is characterized by the loss of the typical peripheral ring of $\beta 1$-tubulin, which forms images similar to balls of yarn (Figure 3, Panel II).

In FLNA-RT, up to one-half of platelets are lacking filamin A staining, while displaying the normal $\beta 1$-tubulin distribution. Another typical feature of FLNA-RT we have observed in our laboratory is diffuse staining of platelets for filamin A, which usually appears as a thick ring (Figure 3, Panel III). 

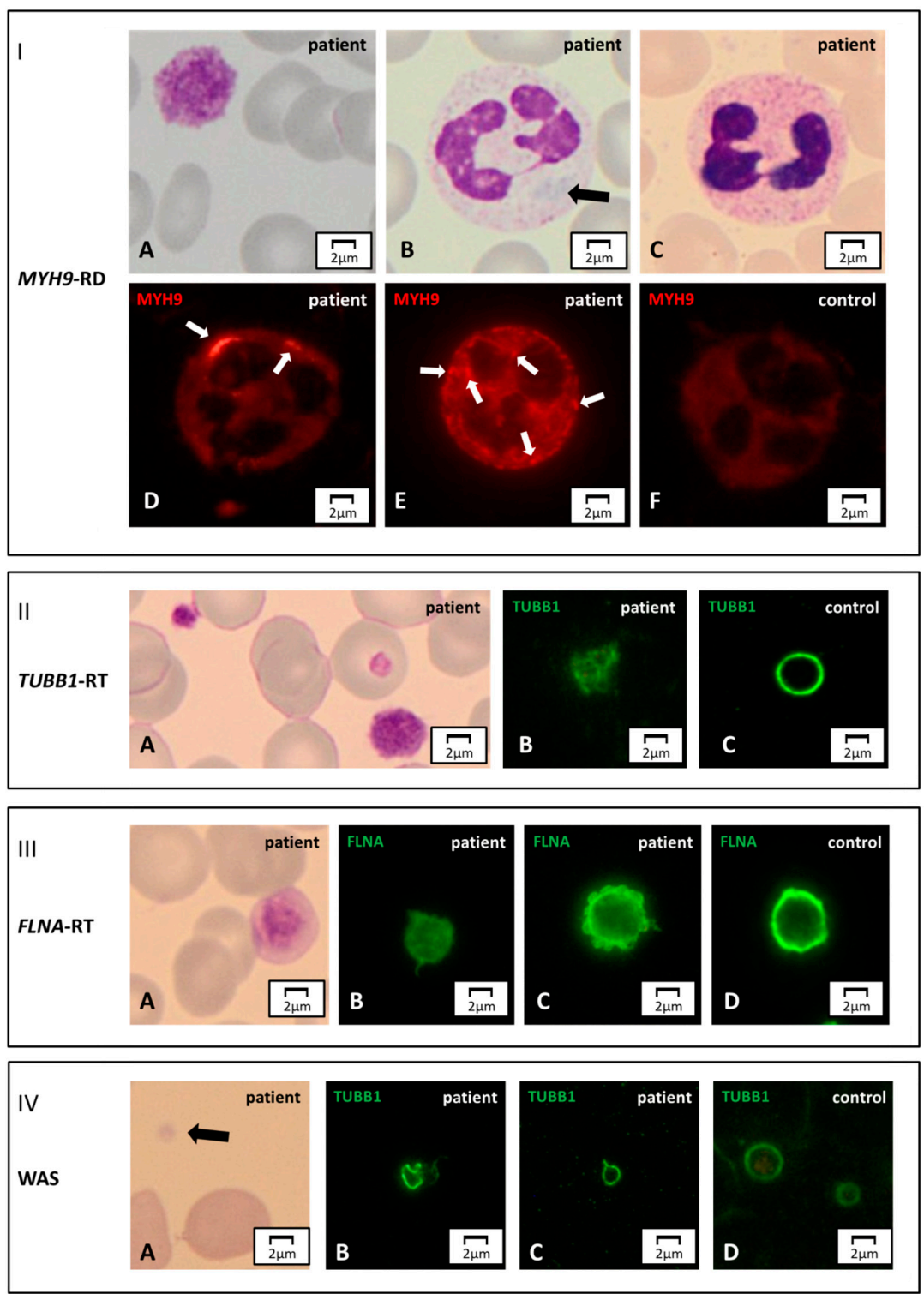

Figure 3. Cytoskeleton markers. Panel I. MYH9-RD. (A) A normal-stained giant platelet and (B) a faint blue Döhle-like body in a neutrophil's cytoplasm of an MYH9-RD patient, by light microscopy. (C) The aggregates of mutated non-muscular myosin II-A heavy chain can be unrecognizable in May-Grünwald Giemsa (MGG)-stained slides, while they are always detectable by immunofluorescence microscopy. (F) In the control, the non-muscular myosin II-A heavy chain signal is diffuse, while in the affected subjects it forms aggregates of different sizes and numbers. (D) Few, large $(2-5 \mu \mathrm{m})$ inclusions are typically observed in patients with mutations hitting the tail domain of MYH9 coded protein. (E) Multiple, smaller $(<0.5 \mu \mathrm{m})$ aggregates are characteristic of patients carrying mutations in the head domain of the same protein. Panel II. TUBB1-related thrombocytopenia (TUBB1-RT). (A) An MGG-stained blood smear of an affected subject displaying large, normal-stained platelets. (B,C) In immunofluorescence, the typical $\beta 1$-tubulin ring (control) is disrupted and resembles a ball of wool. Panel III. FLNA-related thrombocytopenia (FLNA-RT). A) Patients suffering from FLNA-RT have macro-thrombocytopenia with normal granular staining of platelets. (B-D) By immunofluorescence microscopy, filamin A presents altered distribution with respect to the typical peripheral ring-shaped signal (control). In the affected subjects, the filamin A pattern can appear diffused or patched. Panel IV. WAS. (A) Patients distinctively show small platelets in the MGG-stained blood smear. (B-D) The genetic alterations make platelet cytoskeleton stiffer, thus causing an abnormal distribution of $\beta 1$-tubulin by immunofluorescence assessment. With respect to the typical ring (control), it can present stretched or bent. 
The use of an antibody against $\beta 1$-tubulin is also worthwhile to identify some patients with WAS [78]. In this disorder, platelets are reduced in size and may show the abnormal distribution of this cytoskeleton protein that appears stretched or forming uncommon images (e.g., eight-shaped aspect) (Figure 3, Panel IV). However, not all WAS patients show these changes in $\beta 1$-tubulin, and a normal $\beta 1$-tubulin ring does not exclude WAS.

\subsection{Surface Receptors}

Two IPDs can be readily identified by labeling proteins belonging to the membrane receptor complex GpIb/IX/V or GpIIb/IIIa [78].

Patients with biallelic BSS display complete or severe depletion of GpIb/IX (Figure 4, Panel I). Monoallelic form of BSS, having a partial reduction of these glycoproteins, can be sometimes suspected by immunofluorescence. However, immunofluorescence analysis on the blood smear is at best semiquantitative, and reduced surface Gp expression requires confirmation by flow cytometry.

Similarly, in "classic" GT platelets are normal in number and size, but the expression of GpIIb/IIIa on the surface is abolished or severely reduced (Figure 4, Panel II). Only in type 3 (i.e., monoallelic), GT platelets are often enlarged. Immunofluorescence can also reveal a partial reduction of GpIIb/IIIa in type 2 or 3 GT (see comment above).

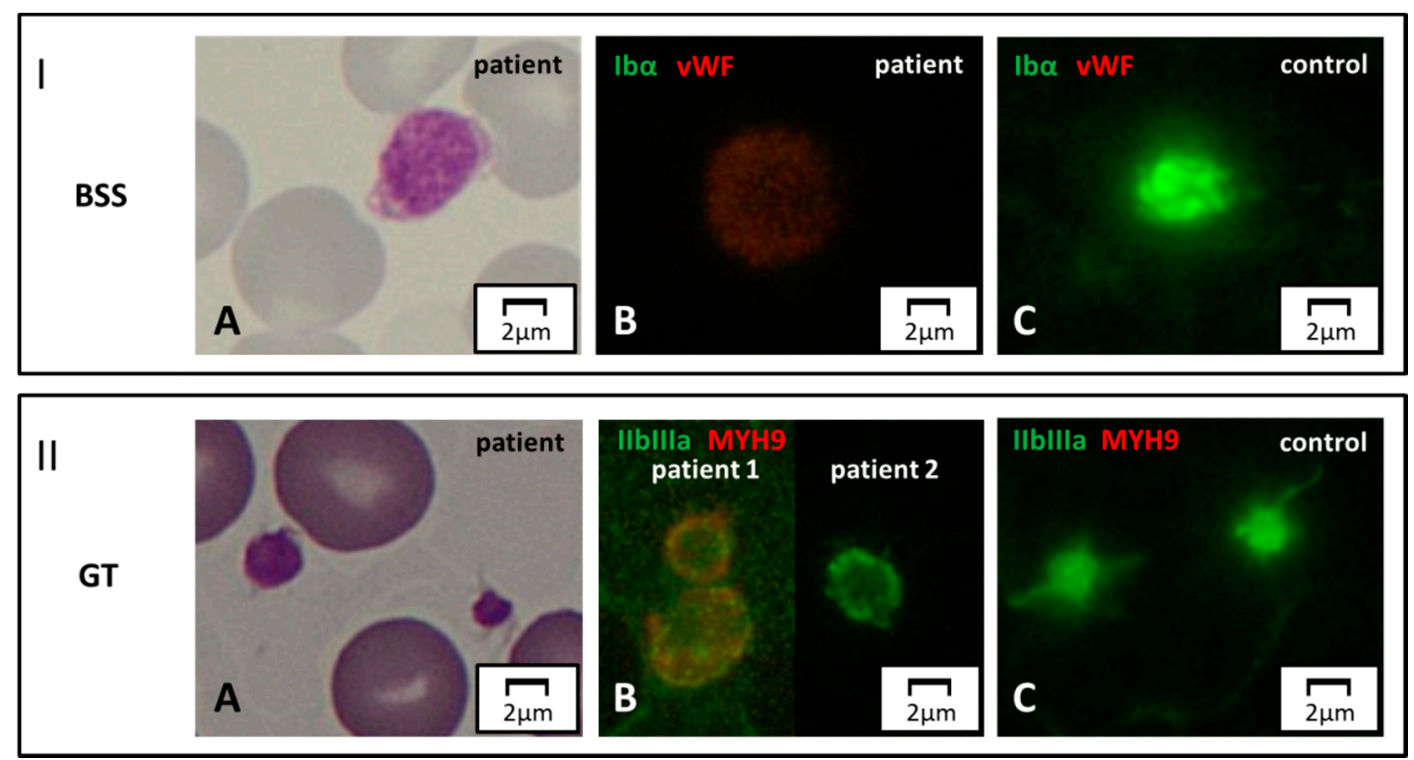

Figure 4. Surface protein markers. Panel I. Bernard-Soulier syndrome (BSS). (A) Light microscopy. A patient affected with biallelic BSS displays a large platelet on MGG-stained blood smear. (B,C) Immunofluorescence microscopy. By labeling for GpIb $\alpha$ (green) and vWF (red), the green signal is completely abolished in the patient due to the absence of the corresponding protein on the surface of platelets. Panel II. GT. (A) Normal-size platelets in a subject affected with GT, by light microscopy. (B,C) In immunofluorescence, complete and partial reduction of the GpIIb/IIIa signal (green) in two patients with respect to control. Note of caution. Although the immunofluorescence pictures are taken by the green-light channel, a dim red signal emerges in some pathologic samples due to counterstaining for a second marker in red (in this case, MYH9).

\subsection{Alpha and Delta Granule Markers}

Labeling for von Willebrand factor (vWF), thrombospondin (TS), and P-selectin (P-sel) enables to detect the lack of $\alpha$-granules, thus confirming GPS [78]. Partial depletion of $\alpha$-granules can refer to two IPDs with a low number of normal or enlarged platelets: GATA1-RT and GFI1B-RT. These forms can be further distinguished in the presence of dyserythropoiesis or by the expression of the stem cell 
antigen CD34 on platelets, respectively [86] (Figure 5). In the absence of thrombocytopenia, a decrease of $\alpha$-granule markers moves towards $\alpha$-SPD (Figure 6, Panel I).

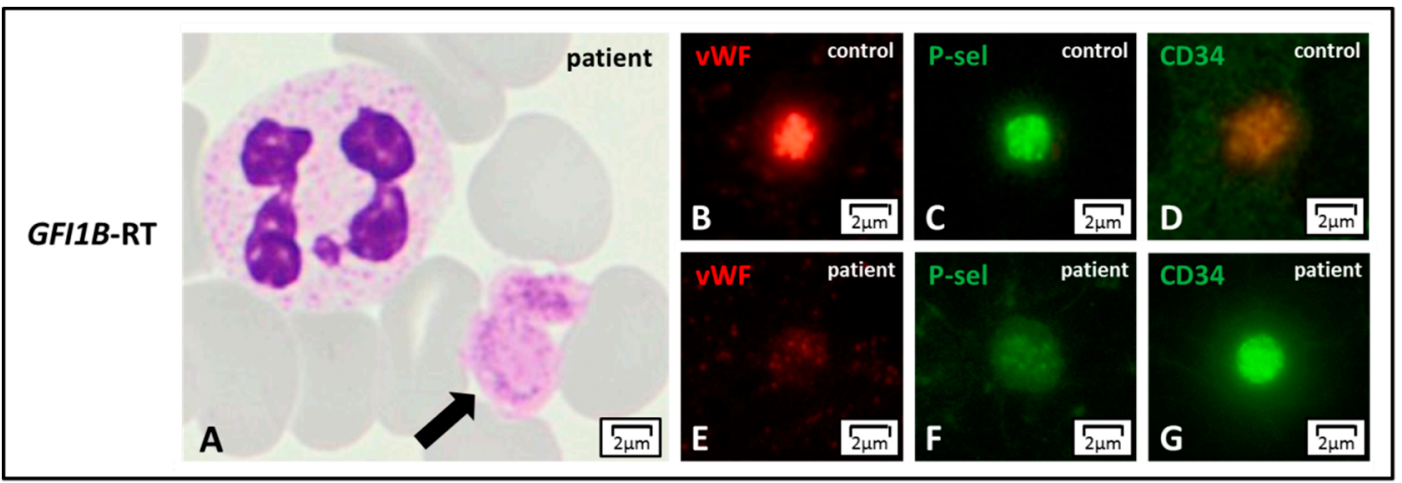

Figure 5. GFI1B-RT. (A) GFI1B-related thrombocytopenia (GFI1B-RT) is characterized by large and pale platelets, by light microscopy. (B-G) The reduction of azurophilic granules' content can be confirmed in immunofluorescence by staining the typical alpha-granule markers such as von Willebrand factor (vWF) or P-selectin (P-sel) that appear reduced with respect to control. Of note, platelets also present CD34 stem cell antigen that is normally not expressed in the controls.

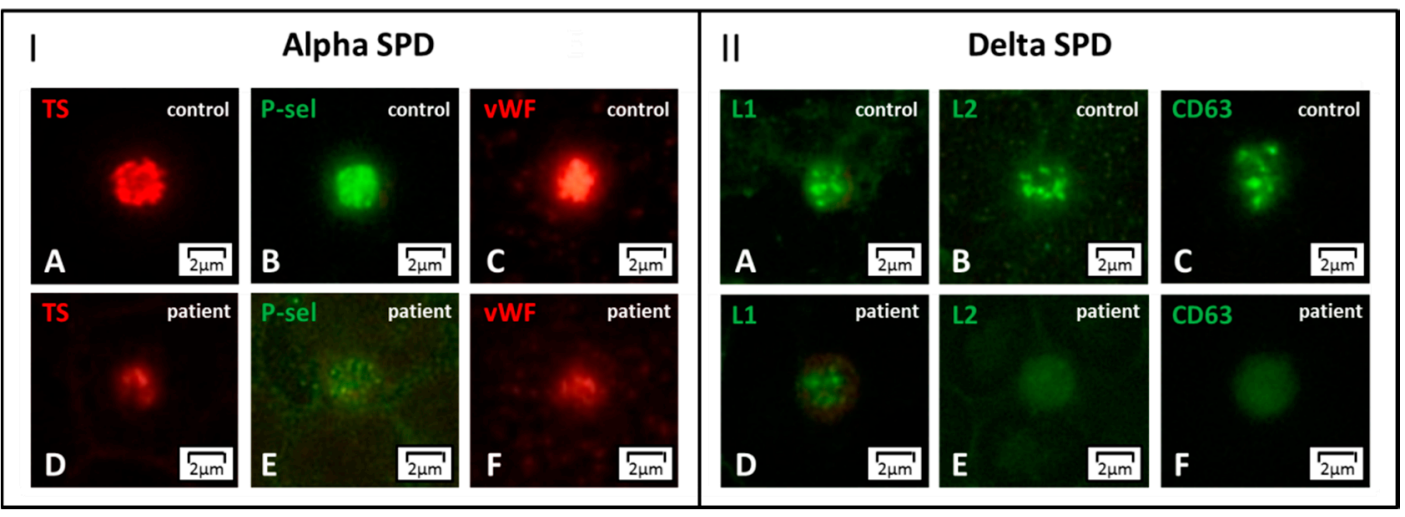

Figure 6. Alpha- and delta storage pool disease (SPD) by immunofluorescence microscopy. Panel I. (A-F) In alpha SPD, the labeling for the alpha-granule markers thrombospondin (TS), P-selectin (P-sel), and von Willebrand factor (vWF) shows significantly reduced staining with respect to control. Panel II. (A-F) In delta SPD, the dense granule markers Lamp 1 (L1), Lamp 2 (L2), and CD63 display diffuse patterns with reduced or even absent granularity. Alpha- and delta SPD can present associated.

A set of dense granule markers as Lamp 1 (L1), which is present also in the lysosomes, Lamp 2 (L2), and CD63, allows identifying forms with $\delta$-granules reduction, $\delta$-SPD (Figure 6, Panel II). If the patient also presents with oculo-cutaneous albinism Hermansky-Pudlak syndrome is the most likely diagnosis. Abnormalities of $\delta$-granule distribution associated with mild thrombocytopenia suggest another IPD, which will be discussed below (i.e., ETV6-RT). Finally, it should be recalled that either acquired platelet defects or preanalytical platelet activation can result in alterations of the distribution of granule markers.

Note of caution. The main pathologic patterns of IPDs reported in Figures 3-6 were obtained by a regular immunofluorescence microscope. By exploiting more sophisticated technologies, such as confocal microscopy, one can achieve higher quality images, as shown, as an example, in Figure 7. It allows us to get better definition and counterstain and to visualize the specific distribution of platelet markers more clearly. In contrast, only a few centers have a confocal microscope available, and the time to obtain the images is longer and not feasible for diagnostic purposes. Since the aim of this review is to guide physicians in the diagnostic work-up of IPDs, we deliberately decided to present primarily 
images obtained by regular immunofluorescence microscopy. Although the recognition of certain pathologic patterns can be more difficult, it is more representative of the real-life diagnostic setting.

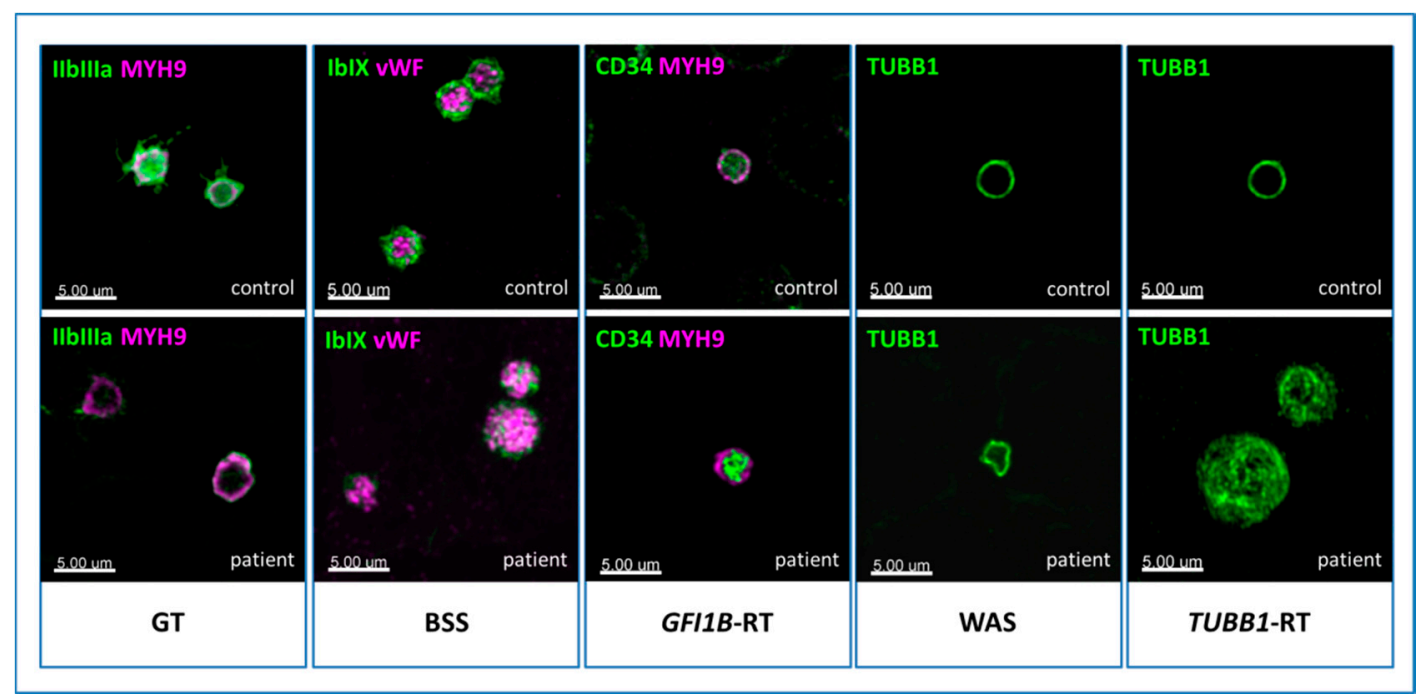

Figure 7. Images of pathologic patterns of five forms of inherited platelet disorder (IPD) obtained by confocal microscopy. Immunofluorescence microscopy. In Glanzmann's thrombasthenia (GT), platelets show almost no GpIIb/IIIa surface receptor (green). In BSS, the signal corresponding to GpIb/IX (green) on the surface is lacking, and only some spots inside the platelets are recognizable, showing the altered protein which cannot be transferred to the membrane. In GFI1B-RT, the stem cell antigen CD34 (green) persists on the platelet surface. Instead of a typical nice ring (controls), the cytoskeleton marker $\beta 1$-tubulin (green) appears twisted in Wiskott-Aldrich syndrome (WAS), and resembles a ball of wool in TUBB1-RT. The healthy controls are shown in the upper pictures.

\section{Weaknesses and Ethical Considerations}

\subsection{Limitations Related to this Method and New Perspectives}

The immune-morphological analysis of blood smears needs skilled operators and can be performed only in specialized centers. This logistic limitation can be easily overcome by shipping samples. With a view to the future, the possibility of automatic or semi-automatic reading of the immunofluorescence patterns is attractive as it could mitigate some logistical difficulties. Similar automated readers are established for routine practice in rheumatology laboratories.

Some preanalytical issues are still debated. First, it has not been clarified whether the smears obtained by finger prick can lead to artifacts by inducing platelet activation. Similarly, also EDTA-dependent platelet pre-activation can alter some morphological parameters on slides obtained by anticoagulated blood [99]. Moreover, spontaneous activation can affect platelet markers, mainly cytoskeleton proteins (e.g., due to preanalytic alterations, signaling defects, or IPDs themselves as type $2 \mathrm{~B} v W D$ or monoallelic GT). None of the morphological markers of platelet activation can differentiate between in-vivo activation and preanalytical arteifacts.

In regard to the diagnostic power, sensitivity, and specificity of the immunofluorescence method seem to be very high in MYH9-RD [78,96,100,101]. Similar performance parameters were found for GT and biallelic BSS [78]. Encouraging data have also been reported about the identification capability of GPS by blood smear assessment [84,102]. About the other forms, due to the scarceness of patients, sensitivity and specificity evaluation are not achievable yet.

When all immune-morphological patterns are normal, the present method can provide rapid help to the differential diagnosis by excluding some IPDs. On the other hand, the global negative predictive value is questionable since other acquired or inherited disorders, causing thrombocytopenia and platelet dysfunction, cannot be excluded nor suggested. 
To face these limitations, further network studies involving a broader number of patients, and sharing samples among laboratories, should be encouraged.

New substantial diagnostic perspectives rely on the identification of specific changes in platelet proteins being recognizable by diagnostic antibodies. A possible diagnostic pattern for ACTN1-related thrombocytopenia has been proposed upon observing the peculiar distribution of MYH9 protein in the granulomere area of surface-activated platelets [103]. Besides, alteration in MYH10 distribution has been reported as a sign of thrombocytopenia due to FLI1 or RUNX1 mutations [104]. On the side of platelet function defects, the possibility to mark phosphorylated proteins along the major signaling pathways seems promising to enlarge the diagnostic spectrum of these disorders [43].

\subsection{Ethical Considerations}

Mainly with the increasing use of NGS, some major ethical issues related to IPDs diagnosis have arisen. They prevalently concern forms conferring the risk of acquired hematological malignancies as ANKRD26-RT, ETV6-RT, and FDP/AML. These disorders are largely characterized by mild thrombocytopenia and minor bleeding tendency. So, at least at the diagnosis stage, their impact on patients' quality of life can be almost negligible. In contrast, the additional information about an increased risk of leukemia can considerably enhance the psychological disease burden of patients and parents (if the patient is a minor). Notably, the global proportion of patients developing hematological malignancies is low, with 10 to $30 \%$ [12,13,35-42]. Moreover, we do not have at now efficient tools to predict the individual risk nor to prevent the development of leukemia.

Currently, experts in the field are discussing the implications of testing for IPDs in regard to IPDs associated with increased risk for hematological malignancies $[77,105]$. Before undergoing genetic testing, patients are usually requested to give informed consent, and they can opt not to receive additional incidental information (e.g., in a female patient, to be a carrier of hemophilia A) [106]. Conversely, in the IPDs setting of ANKRD26-RT, ETV6-RT, and FDP/AML, it is not possible to separate the diagnostic- from the predictive value of the mutation. Also, immunofluorescence testing can raise the suspicion at least for ETV6-RT. In eight out of nine patients suffering from this form, detectable ETV6 proteins within the platelet cytoplasm (absent in the healthy controls) have been reported. Likewise, dense granule markers L2 and CD63 were diminished and diffusely distributed in ETV6-RT platelets [107]. Before including antibodies staining for ETV6 into the panel, specific consent should be obtained from the patient.

\section{Conclusions}

The diagnostic method to identify IPDs using a blood smear presents a helpful "platform of action". It allows rather extended diagnosis in young children using minimal amounts of blood. Blood smears can be easily prepared even at sites far away from specialized laboratories and can be mailed for further diagnostic workup. The method powerfully suggests diagnosis in some cases (e.g., MYH9-RD, GT, and BSS), making it possible to achieve the genetic confirmation restricted to the gene of interest. A recapitulatory, guidance flow-chart for diagnostic testing for IPDs is shown in Figure 8.

Except a few selected forms, the main benefit of a confirmed diagnosis of IPD is to avoid over-treatment. In fact, one of the main risks of these patients is to be misdiagnosed as having immune thrombocytopenia (ITP) or, less frequently, myelodysplastic syndrome. These misdiagnoses seriously impact their management by exposing patients to ineffective and potentially harmful treatments such as splenectomy, immunosuppression, or chemotherapy [32,51,108].

To progressively understand IPDs, further characterization of patients is highly relevant. The combination of genetic testing, together with detailed phenotypic characterization and systems biology studies in the laboratory are essential. Immunofluorescence analysis of platelets on a blood smear is one of the new tools contributing to these joint efforts. Moreover, it allows the rapid translational application of new findings on IPDs obtained by research laboratories using mouse models and cultured Mks into clinical practice. 


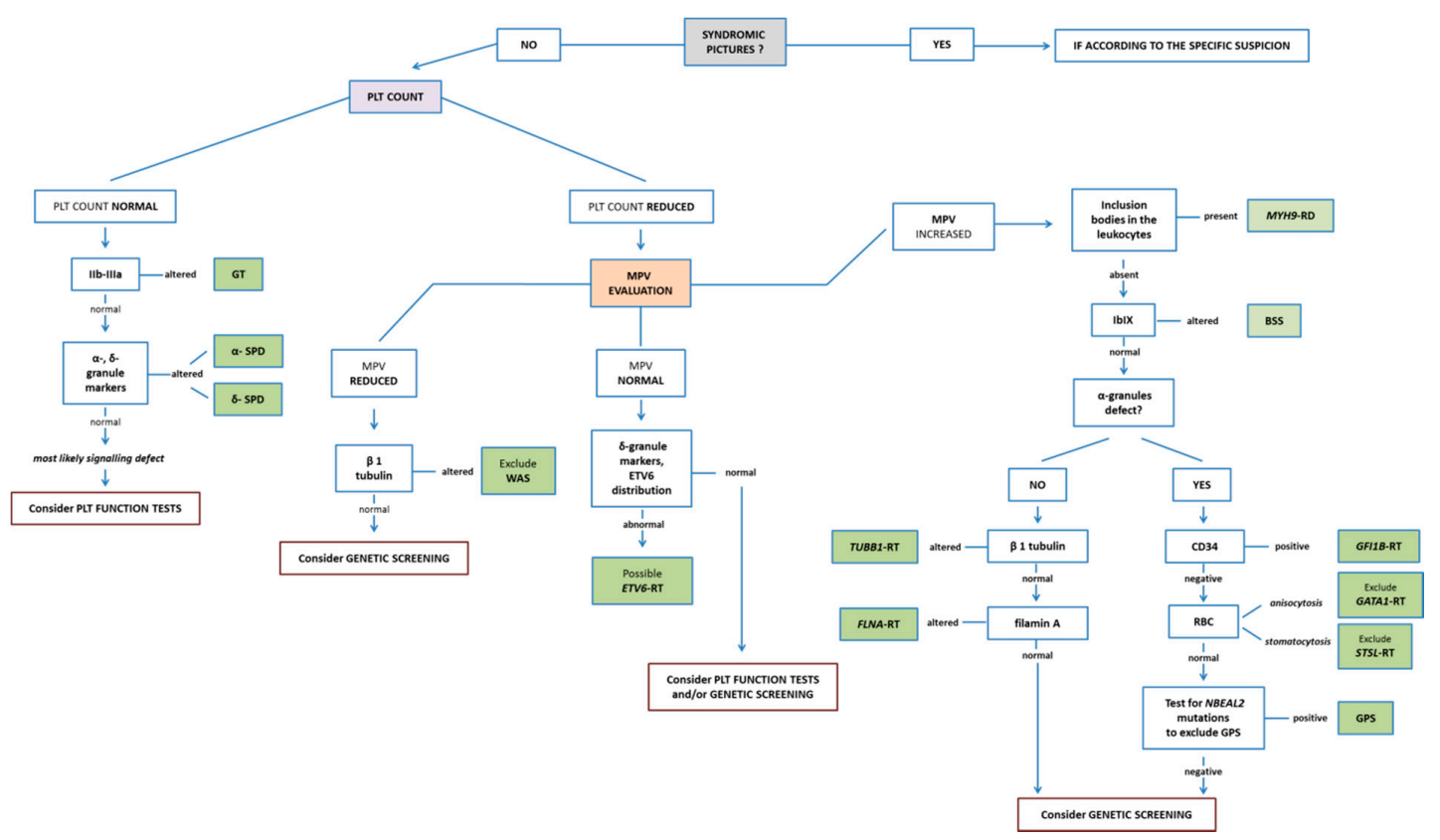

Figure 8. Proposal of a diagnostic algorithm for IPDs. According to peculiar clinical pictures (e.g., syndromic forms of IPD), or the evaluation of platelet number and size, the specific markers to be evaluated stepwise using light- and immunofluorescence microscopy are reported. Although the present diagnostic algorithm is primarily based on the evaluation of the blood smear, the use of further diagnostic tools such as platelet function tests and genetic screening should also be taken into account.

Author Contributions: A.G. and C.Z. drafted the concept and wrote the manuscript. All authors have read and agreed to the published version of the manuscript.

Funding: This research was funded by the Deutsche Forschungsgemeinschaft (DFG, German Research Foundation)-Projektnummer 374031971-TRR 240. The APC was funded by Universitätsmedizin Greifswald.

Acknowledgments: The authors acknowledge the colleagues referring patients and providing clinical information, and other researchers who perform genetic testing for IPDs. The work of Marcel Baschin and Carmen Freyer, who perform the immunofluorescence analysis of platelets in Greifswald laboratory, is highly appreciated.

Conflicts of Interest: None of the authors has to declare a conflict of interest in the context of this work.

\section{References}

1. Noris, P.; Pecci, A. Hereditary thrombocytopenias: A growing list of disorders. Hematology 2017, 2017, 385-399. [CrossRef] [PubMed]

2. Lentaigne, C.; Greene, D.; Sivapalaratnam, S.; Favier, R.; Seyres, D.; Thys, C.; Grassi, L.; Mangles, S.; Sibson, K.; Stubbs, M.J.; et al. Germline mutations in the transcription factor IKZF5 cause thrombocytopenia. Blood 2019, 134, 2070-2081. [CrossRef] [PubMed]

3. Almazni, I.; Stapley, R.; Morgan, N.V. Inherited Thrombocytopenia: Update on Genes and Genetic Variants which may be Associated with Bleeding. Front. Cardiovasc. Med. 2019, 6, 80. [CrossRef]

4. Bastida, J.M.; Lozano, M.L.; Benito, R.; Janusz, K.; Palma-Barqueros, V.; Del Rey, M.; Hernández-Sánchez, J.M.; Riesco, S.; Bermejo, N.; González-García, H.; et al. Introducing high-throughput sequencing into mainstream genetic diagnosis practice in inherited platelet disorders. Haematologica 2018, 103, 148-162. [CrossRef] [PubMed]

5. Freson, K.; Turro, E. High-throughput sequencing approaches for diagnosing hereditary bleeding and platelet disorders. J. Thromb. Haemost. 2017, 15, 1262-1272. [CrossRef] [PubMed] 
6. Leinøe, E.; Zetterberg, E.; Kinalis, S.; Østrup, O.; Kampmann, P.; Norström, E.; Andersson, N.; Klintman, J.; Qvortrup, K.; Nielsen, F.C.; et al. Application of whole-exome sequencing to direct the specific functional testing and diagnosis of rare inherited bleeding disorders in patients from the Öresund Region, Scandinavia. Br. J. Haematol. 2017, 179, 308-322. [CrossRef]

7. Lentaigne, C.; Freson, K.; Laffan, M.A.; Turro, E.; Ouwehand, W.H. Inherited platelet disorders: Toward DNA-based diagnosis. Blood 2016, 127, 2814-2823. [CrossRef]

8. Vannucchi, A.M. Pegasus causes inherited thrombocytopenia. Blood 2019, 134, 2000-2002. [CrossRef]

9. Pecci, A.; Balduini, C.L. Lessons in platelet production from inherited thrombocytopenias. Br. J. Haematol. 2014, 165, 179-192. [CrossRef]

10. Hirata, S.; Takayama, N.; Jono-Ohnishi, R.; Endo, H.; Nakamura, S.; Dohda, T.; Nishi, M.; Hamazaki, Y.; Ishii, E.I.; Kaneko, S.; et al. Congenital amegakaryocytic thrombocytopenia iPS cells exhibit defective MPL-mediated signaling. J. Clin. Investig. 2013, 123, 3802-3814. [CrossRef]

11. Songdej, N.; Rao, A.K. Hematopoietic transcription factor mutations: Important players in inherited platelet defects. Blood 2017, 129, 2873-2881. [CrossRef]

12. Noetzli, L.; Lo, R.W.; Lee-Sherick, A.B.; Callaghan, M.; Noris, P.; Savoia, A.; Rajpurkar, M.; Jones, K.; Gowan, K.; Balduini, C.L.; et al. Germline mutations in ETV6 are associated with thrombocytopenia, red cell macrocytosis and predisposition to lymphoblastic leukemia. Nat. Genet. 2015, 47, 535-538. [CrossRef] [PubMed]

13. Sakurai, M.; Kasahara, H.; Yoshida, K.; Yoshimi, A.; Kunimoto, H.; Watanabe, N.; Shiraishi, Y.; Chiba, K.; Tanaka, H.; Harada, Y.; et al. Genetic basis of myeloid transformation in familial platelet disorder/acute myeloid leukemia patients with haploinsufficient RUNX1 allele. Blood Cancer J. 2016, 6, e392. [CrossRef] [PubMed]

14. Karastaneva, A.; Nebral, K.; Schlagenhauf, A.; Baschin, M.; Palankar, R.; Juch, H.; Heitzer, E.; Speicher, M.R.; Höfler, G.; Grigorow, I.; et al. Novel phenotypes observed in patients with ETV6-linked leukaemia/familial thrombocytopenia syndrome and a biallelic ARID5B risk allele as leukaemogenic cofactor. J. Med. Genet. 2019. [CrossRef]

15. Pecci, A.; Malara, A.; Badalucco, S.; Bozzi, V.; Torti, M.; Balduini, C.L.; Balduini, A. Megakaryocytes of patients with MYH9-related thrombocytopenia present an altered proplatelet formation. Thromb. Haemost. 2009, 102, 90-96.

16. Kunishima, S.; Kobayashi, R.; Itoh, T.J.; Hamaguchi, M.; Saito, H. Mutation of the $\beta 1$-tubulin gene associated with congenital macrothrombocytopenia affecting microtubule assembly. Blood 2009, 113, 458-461. [CrossRef]

17. Nurden, P.; Debili, N.; Coupry, I.; Bryckaert, M.; Youlyouz-Marfak, I.; Solé, G.; Pons, A.C.; Berrou, E.; Adam, F.; Kauskot, A.; et al. Thrombocytopenia resulting from mutations in filamin A can be expressed as an isolated syndrome. Blood 2011, 118, 5928-5937. [CrossRef]

18. Kunishima, S.; Okuno, Y.; Yoshida, K.; Shiraishi, Y.; Sanada, M.; Muramatsu, H.; Chiba, K.; Tanaka, H.; Miyazaki, K.; Sakai, M.; et al. ACTN1 mutations cause congenital macrothrombocytopenia. Am. J. Hum. Genet. 2013, 92, 431-438. [CrossRef]

19. Futterer, J.; Dalby, A.; Lowe, G.C.; Johnson, B.; Simpson, M.A.; Motwani, J.; Williams, M.; Watson, S.P.; Morgan, N.V. Mutation in GNE is associated with severe congenital thrombocytopenia. Blood 2018, 132, 1855-1858. [CrossRef]

20. Revel-Vilk, S.; Shai, E.; Turro, E.; Jahshan, N.; Hi-Am, E.; Spectre, G.; Daum, H.; Kalish, Y.; Althaus, K.; Greinacher, A.; et al. GNE variants causing autosomal recessive macrothrombocytopenia without associated muscle wasting. Blood 2018, 132, 1851-1854. [CrossRef]

21. Kraemer, B.F.; Weyrich, A.S. Insight Increased formation of PaCSs in megakaryocytes and platelets from patients with autosomal-dominant ANKRD26-related thrombocytopenia: Polyubiquinated protein depots in platelets and megakaryocytes from patients with ANKRD26-RT. Thromb. Haemost. 2012, 109, 180. [CrossRef] [PubMed]

22. Necchi, V.; Balduini, A.; Noris, P.; Barozzi, S.; Sommi, P.; di Buduo, C.; Balduini, C.L.; Solcia, E.; Pecci, A. Ubiquitin/proteasome-rich particulate cytoplasmic structures (PaCSs) in the platelets and megakaryocytes of ANKRD26-related thrombocytopenia. Thromb. Haemost. 2013, 109, 263-271. [CrossRef] [PubMed] 
23. Gresele, P.; Orsini, S.; Noris, P.; Falcinelli, E.; Alessi, M.C.; Bury, L.; Borhany, M.; Santoro, C.; Glembotsky, A.C.; Cid, A.R.; et al. Study investigators. Validation of the ISTH/SSC bleeding assessment tool for inherited platelet disorders: A communication from the Platelet Physiology SSC. J. Thromb. Haemost. 2019. [CrossRef] [PubMed]

24. Orsini, S.; Noris, P.; Bury, L.; Heller, P.G.; Santoro, C.; Kadir, R.A.; Butta, N.C.; Falcinelli, E.; Cid, A.R.; Fabris, F.; et al. Bleeding risk of surgery and its prevention in patients with inherited platelet disorders. Haematologica 2017, 102, 1192-1203. [CrossRef]

25. Toriello, H.V. Thrombocytopenia-absent radius syndrome. Semin. Thromb. Hemost. 2011, 37, 707-712. [CrossRef]

26. Niihori, T.; Ouchi-Uchiyama, M.; Sasahara, Y.; Kaneko, T.; Hashii, Y.; Irie, M.; Sato, A.; Saito-Nanjo, Y.; Funayama, R.; Nagashima, T.; et al. Mutations in MECOM, Encoding Oncoprotein EVI1, Cause Radioulnar Synostosis with Amegakaryocytic Thrombocytopenia. Am. J. Hum. Genet. 2015, 97, 848-854. [CrossRef]

27. Candotti, F. Clinical Manifestations and Pathophysiological Mechanisms of the Wiskott-Aldrich Syndrome. J. Clin. Immunol. 2018, 38, 13-27. [CrossRef]

28. Albert, M.H.; Bittner, T.C.; Nonoyama, S.; Notarangelo, L.D.; Burns, S.; Imai, K.; Espanol, T.; Fasth, A.; Pellier, I.; Strauss, G.; et al. X-linked thrombocytopenia (XLT) due to WAS mutations: Clinical characteristics, long-term outcome, and treatment options. Blood 2010, 115, 3231-3238. [CrossRef]

29. Freson, K.; Wijgaerts, A.; Van Geet, C. GATA1 gene variants associated with thrombocytopenia and anemia. Platelets 2017, 28, 731-734. [CrossRef]

30. Nesin, V.; Wiley, G.; Kousi, M.; Ong, E.C.; Lehmann, T.; Nicholl, D.J.; Suri, M.; Shahrizaila, N.; Katsanis, N.; Gaffney, P.M.; et al. Activating mutations in STIM1 and ORAI1 cause overlapping syndromes of tubular myopathy and congenital miosis. Proc. Natl. Acad. Sci. USA 2014, 111, 4197-4202. [CrossRef]

31. Markello, T.; Chen, D.; Kwan, J.Y.; Horkayne-Szakaly, I.; Morrison, A.; Simakova, O.; Maric, I.; Lozier, J.; Cullinane, A.R.; Kilo, T.; et al. York platelet syndrome is a CRAC channelopathy due to gain-of-function mutations in STIM1. Mol. Genet. Metab. 2015, 114, 474-482. [CrossRef]

32. Pecci, A.; Klersy, C.; Gresele, P.; Lee, K.J.D.; De Rocco, D.; Bozzi, V.; Russo, G.; Heller, P.G.; Loffredo, G.; Ballmaier, M.; et al. MYH9-related disease: A novel prognostic model to predict the clinical evolution of the disease based on genotype-phenotype correlations. Hum. Mutat. 2014, 35, 236-247. [CrossRef] [PubMed]

33. Stritt, S.; Nurden, P.; Turro, E.; Greene, D.; Jansen, S.B.; Westbury, S.K.; Petersen, R.; Astle, W.J.; Marlin, S.; Bariana, T.K.; et al. A gain-of-function variant in DIAPH1 causes dominant macrothrombocytopenia and hearing loss. Blood 2016, 127, 2903-2914. [CrossRef] [PubMed]

34. Ballmaier, M.; Germeshausen, M. Congenital amegakaryocytic thrombocytopenia: Clinical presentation, diagnosis, and treatment. Semin. Thromb. Hemost. 2011, 37, 673-681. [CrossRef]

35. Arber, D.A. The 2016 WHO classification of acute myeloid leukemia: What the practicing clinician needs to know. Semin. Hematol. 2019, 56, 90-95. [CrossRef] [PubMed]

36. Galera, P.; Dulau-Florea, A.; Calvo, K.R. Inherited thrombocytopenia and platelet disorders with germline predisposition to myeloid neoplasia. Int. J. Lab. Hematol. 2019, 41, 131-141. [CrossRef] [PubMed]

37. Noris, P.; Perrotta, S.; Seri, M.; Pecci, A.; Gnan, C.; Loffredo, G.; Pujol-Moix, N.; Zecca, M.; Scognamiglio, F.; De Rocco, D.; et al. Mutations in ANKRD26 are responsible for a frequent form of inherited thrombocytopenia: Analysis of 78 patients from 21 families. Blood 2011, 117, 6673-6680. [CrossRef] [PubMed]

38. Noris, P.; Favier, R.; Alessi, M.C.; Geddis, A.E.; Kunishima, S.; Heller, P.G.; Giordano, P.; Niederhoffer, K.Y.; Bussel, J.B.; Podda, G.M.; et al. ANKRD26-related thrombocytopenia and myeloid malignancies. Blood 2013, 122, 1987-1989. [CrossRef]

39. Zhang, M.Y.; Churpek, J.E.; Keel, S.B.; Walsh, T.; Lee, M.K.; Loeb, K.R.; Gulsuner, S.; Pritchard, C.C.; Sanchez-Bonilla, M.; Delrow, J.J.; et al. Germline ETV6 mutations in familial thrombocytopenia and hematologic malignancy. Nat. Genet. 2015, 47, 180-185. [CrossRef]

40. Melazzini, F.; Palombo, F.; Balduini, A.; De Rocco, D.; Marconi, C.; Noris, P.; Gnan, C.; Pippucci, T.; Bozzi, V.; Faleschini, M.; et al. Clinical and pathogenic features of ETV6-related thrombocytopenia with predisposition to acute lymphoblastic leukemia. Haematologica 2016, 101, 1333-1342. [CrossRef]

41. Moriyama, T.; Metzger, M.L.; Wu, G.; Nishii, R.; Qian, M.; Devidas, M.; Yang, W.; Cheng, C.; Cao, X.; Quinn, E.; et al. Germline genetic variation in ETV6 and risk of childhood acute lymphoblastic leukaemia: A systematic genetic study. Lancet Oncol. 2015, 16, 1659-1666. [CrossRef] 
42. Owen, C.J.; Toze, C.L.; Koochin, A.; Forrest, D.L.; Smith, C.A.; Stevens, J.M.; Jackson, S.C.; Poon, M.C.; Sinclair, G.D.; Leber, B.; et al. Five new pedigrees with inherited RUNX1 mutations causing familial platelet disorder with propensity to myeloid malignancy. Blood 2008, 112, 4639-4645. [CrossRef]

43. Turro, E.; Greene, D.; Wijgaerts, A.; Thys, C.; Lentaigne, C.; Bariana, T.K.; Westbury, S.K.; Kelly, A.M.; Selleslag, D.; Stephens, J.C.; et al. A dominant gain-of-function mutation in universal tyrosine kinase SRC causes thrombocytopenia, myelofibrosis, bleeding, and bone pathologies. Sci. Transl. Med. 2016, 8, 328 ra30. [CrossRef] [PubMed]

44. Saultier, P.; Alessi, M.C.; Michel, G.; Chambost, H. Hematopoietic stem cell transplantation for the treatment of leukocyte adhesion deficiency type III. Pediatr. Neonatol. 2017, 58, 560-561. [CrossRef] [PubMed]

45. Elfeky, R.A.; Furtado-Silva, J.M.; Chiesa, R.; Rao, K.; Amrolia, P.; Lucchini, G.; Gilmour, K.; Adams, S.; Bibi, S.; Worth, A.; et al. One hundred percent survival after transplantation of 34 patients with Wiskott-Aldrich syndrome over 20 years. J. Allergy Clin. Immunol. 2018, 142, 1654-1656. [CrossRef] [PubMed]

46. Winikoff, R.; Scully, M.F.; Robinson, K.S. Women and inherited bleeding disorders-A review with a focus on key challenges for 2019. Transfus. Apher. Sci. 2019, 58, 613-622. [CrossRef] [PubMed]

47. Colucci, G.; Stutz, M.; Rochat, S.; Conte, T.; Pavicic, M.; Reusser, M.; Giabbani, E.; Huynh, A.; Thürlemann, C.; Keller, P.; et al. The effect of desmopressin on platelet function: A selective enhancement of procoagulant COAT platelets in patients with primary platelet function defects. Blood 2014, 123, 1905-1916. [CrossRef]

48. Bolton-Maggs, P.H.B.; Chalmers, E.A.; Collins, P.W.; Harrison, P.; Kitchen, S.; Liesner, R.J.; Minford, A.; Mumford, A.D.; Parapia, L.A.; Perry, D.J.; et al. A review of inherited platelet disorders with guidelines for their management on behalf of the UKHCDO. Br. J. Haematol. 2006, 135, 603-633. [CrossRef]

49. Estcourt, L.J.; Birchall, J.; Allard, S.; Bassey, S.J.; Hersey, P.; Kerr, J.P.; Mumford, A.D.; Stanworth, S.J.; Tinegate, H. Guidelines for the use of platelet transfusions. Br. J. Haematol. 2017, 176, 365-394. [CrossRef]

50. Kaufman, R.M.; Djulbegovic, B.; Gernsheimer, T.; Kleinman, S.; Tinmouth, A.T.; Capocelli, K.E.; Cipolle, M.D.; Cohn, C.S.; Fung, M.K.; Grossman, B.J.; et al. Platelet transfusion: A clinical practice guideline from the AABB. Ann. Intern. Med. 2015, 162, 205-213. [CrossRef]

51. Noris, P.; Schlegel, N.; Klersy, C.; Heller, P.G.; Civaschi, E.; Pujol-Moix, N.; Fabris, F.; Favier, R.; Gresele, P.; Latger-Cannard, V.; et al. Analysis of 339 pregnancies in 181 women with 13 different forms of inherited thrombocytopenia. Haematologica 2014, 99, 1387-1394. [CrossRef] [PubMed]

52. Zaninetti, C.; Gresele, P.; Bertomoro, A.; Klersy, C.; De Candia, E.; Veneri, D.; Barozzi, S.; Fierro, T.; Alberelli, M.A.; Musella, V.; et al. Eltrombopag for the treatment of inherited thrombocytopenias: A phase 2 clinical trial. Haematologica 2019. [CrossRef] [PubMed]

53. Zaninetti, C.; Barozzi, S.; Bozzi, V.; Gresele, P.; Balduini, C.L.; Pecci, A. Eltrombopag in preparation for surgery in patients with severe MYH9-related thrombocytopenia. Am. J. Hematol. 2019, 94, E199-E201. [CrossRef] [PubMed]

54. Ozsahin, H.; Cavazzana-Calvo, M.; Notarangelo, L.D.; Schulz, A.; Thrasher, A.J.; Mazzolari, E.; Slatter, M.A.; Le Deist, F.; Blanche, S.; Veys, P.; et al. Long-term outcome following hematopoietic stem-cell transplantation in Wiskott-Aldrich syndrome: Collaborative study of the European Society for Immunodeficiencies and European Group for Blood and Marrow Transplantation. Blood 2008, 111, 439-445. [CrossRef] [PubMed]

55. Aiuti, A.; Biasco, L.; Scaramuzza, S.; Ferrua, F.; Cicalese, M.P.; Baricordi, C.; Dionisio, F.; Calabria, A.; Giannelli, S.; Castiello, M.C.; et al. Lentiviral hematopoietic stem cell gene therapy in patients with wiskott-aldrich syndrome. Science 2013, 341, 123351. [CrossRef]

56. Gerrits, A.J.; Leven, E.A.; Frelinger, A.L.; Brigstocke, S.L.; Berny-Lang, M.A.; Mitchell, W.B.; Revel-Vilk, S.; Tamary, H.; Carmichael, S.L.; Barnard, M.R.; et al. Effects of eltrombopag on platelet count and platelet activation in Wiskott-Aldrich syndrome/X-linked thrombocytopenia. Blood 2015, 126, 1367-1378. [CrossRef]

57. Pecci, A.; Granata, A.; Fiore, C.E.; Balduini, C.L. Renin-angiotensin system blockade is effective in reducing proteinuria of patients with progressive nephropathy caused by MYH9 mutations (Fechtner-Epstein syndrome). Nephrol. Dial. Transplant. 2008, 23, 2690-2692. [CrossRef]

58. Pecci, A.; Verver, E.J.; Schlegel, N.; Canzi, P.; Boccio, C.M.; Platokouki, H.; Krause, E.; Benazzo, M.; Topsakal, V.; Greinacher, A. Cochlear implantation is safe and effective in patients with MYH9-related disease. Orphanet J. Rare Dis. 2014, 9, 100. [CrossRef]

59. Balduini, C.L.; Pecci, A.; Savoia, A. Recent advances in the understanding and management of MYH9-related inherited thrombocytopenias. Br. J. Haematol. 2011, 154, 161-174. [CrossRef] 
60. Rodeghiero, F.; Tosetto, A.; Abshire, T.; Arnold, D.M.; Coller, B.; James, P.; Neunert, C.; Lillicrap, D. ISTH/SSC bleeding assessment tool: A standardized questionnaire and a proposal for a new bleeding score for inherited bleeding disorders. J. Thromb. Haemost. 2010, 8, 2063-2065. [CrossRef]

61. Noris, P.; Biino, G.; Pecci, A.; Civaschi, E.; Savoia, A.; Seri, M.; Melazzini, F.; Loffredo, G.; Russo, G.; Bozzi, V.; et al. Platelet diameters in inherited thrombocytopenias: Analysis of 376 patients with all known disorders. Blood 2014, 124, e4-e10. [CrossRef] [PubMed]

62. Gresele, P.; Bury, L.; Falcinelli, E. Inherited platelet function disorders: Algorithms for phenotypic and genetic investigation. Semin. Thromb. Hemost. 2016, 42, 292-305. [PubMed]

63. Cattaneo, M.; Cerletti, C.; Harrison, P.; Hayward, C.P.M.; Kenny, D.; Nugent, D.; Nurden, P.; Rao, A.K.; Schmaier, A.H.; Watson, S.P.; et al. Recommendations for the standardization of light transmission aggregometry: A consensus of the working party from the platelet physiology subcommittee of SSC/ISTH. J. Thromb. Haemost. 2013, 11, 1183-1189. [CrossRef] [PubMed]

64. Harrison, P.; Mackie, I.; Mumford, A.; Briggs, C.; Liesner, R.; Winter, M.; Machin, S. Guidelines for the laboratory investigation of heritable disorders of platelet function. Br. J. Haematol. 2011, 155, 30-44. [CrossRef]

65. Hechler, B.; Dupuis, A.; Mangin, P.H.; Gachet, C. Platelet preparation for function testing in the laboratory and clinic: Historical and practical aspects. Res. Pract. Thromb. Haemost. 2019, 3, 615-625. [CrossRef]

66. Bastida, J.M.; Benito, R.; Lozano, M.L.; Marín-Quilez, A.; Janusz, K.; Martín-Izquierdo, M.; Hernández-Sánchez, J.; Palma-Barqueros, V.; Hernández-Rivas, J.M.; Rivera, J.; et al. Molecular Diagnosis of Inherited Coagulation and Bleeding Disorders. Semin. Thromb. Hemost. 2019, 45, 695-707. [CrossRef]

67. Andres, O.; König, E.-M.; Althaus, K.; Bakchoul, T.; Bugert, P.; Eber, S.; Knöfler, R.; Kunstmann, E.; Manukjan, G.; Meyer, O.; et al. Use of Targeted High-Throughput Sequencing for Genetic Classification of Patients with Bleeding Diathesis and Suspected Platelet Disorder. TH Open 2018, 2, e445-e454. [CrossRef]

68. Heremans, J.; Freson, K. High-throughput sequencing for diagnosing platelet disorders: Lessons learned from exploring the causes of bleeding disorders. Int. J. Lab. Hematol. 2018, 40, 89-96. [CrossRef]

69. Johnson, B.; Doak, R.; Allsup, D.; Astwood, E.; Evans, G.; Grimley, C.; James, B.; Myers, B.; Stokley, S.; Thachil, J.; et al. A comprehensive targeted next-generation sequencing panel for genetic diagnosis of patients with suspected inherited thrombocytopenia. Res. Pract. Thromb. Haemost. 2018, 2, 640-652. [CrossRef]

70. Wang, Q.; Cao, L.; Sheng, G.; Shen, H.; Ling, J.; Xie, J.; Ma, Z.; Yin, J.; Wang, Z.; Yu, Z.; et al. Application of High-Throughput Sequencing in the Diagnosis of Inherited Thrombocytopenia. Clin. Appl. Thromb. 2018, 24, 94S-103S. [CrossRef]

71. Maclachlan, A.; Watson, S.P.; Morgan, N.V. Inherited platelet disorders: Insight from platelet genomics using next-generation sequencing. Platelets 2017, 28, 14-19. [CrossRef] [PubMed]

72. Simeoni, I.; Stephens, J.C.; Hu, F.; Deevi, S.V.V.; Megy, K.; Bariana, T.K.; Lentaigne, C.; Schulman, S.; Sivapalaratnam, S.; Vries, M.J.A.; et al. A high-throughput sequencing test for diagnosing inherited bleeding, thrombotic, and platelet disorders. Blood 2016, 127, 2791-2803. [CrossRef] [PubMed]

73. Romasko, E.J.; Devkota, B.; Biswas, S.; Jayaraman, V.; Rajagopalan, R.; Dulik, M.C.; Thom, C.S.; Choi, J.; Jairam, S.; Scarano, M.I.; et al. Utility and limitations of exome sequencing in the molecular diagnosis of pediatric inherited platelet disorders. Am. J. Hematol. 2018, 93, 8-16. [CrossRef] [PubMed]

74. Watson, S.P.; Lowe, G.C.; Lordkipanidzé, M.; Morgan, N.V. Genotyping and phenotyping of platelet function disorders. J. Thromb. Haemost. 2013, 11, 351-363. [CrossRef] [PubMed]

75. Cooper, D.N.; Ball, E.V.; Krawczak, M. The human gene mutation database. Nucleic Acids Res. 1998, 26, 285-287. [CrossRef]

76. Stenson, P.D.; Mort, M.; Ball, E.V.; Howells, K.; Phillips, A.D.; Cooper, D.N.; Thomas, N.S.T. The human gene mutation database: 2008 update. Genome Med. 2009, 1, 13. [CrossRef]

77. Downes, K.; Megy, K.; Duarte, D.; Vries, M.; Gebhart, J.; Hofer, S.; Shamardina, O.; Deevi, S.V.V.; Stephens, J.; Mapeta, R.; et al. Diagnostic high-throughput sequencing of 2,396 patients with bleeding, thrombotic and platelet disorders. Blood 2019, 134, 2082-2091. [CrossRef]

78. Greinacher, A.; Pecci, A.; Kunishima, S.; Althaus, K.; Nurden, P.; Balduini, C.L.; Bakchoul, T. Diagnosis of inherited platelet disorders on a blood smear: A tool to facilitate worldwide diagnosis of platelet disorders. J. Thromb. Haemost. 2017, 15, 1511-1521. [CrossRef]

79. Greinacher, A.; Eekels, J.J.M. Simplifying the diagnosis of inherited platelet disorders? The new tools do not make it any easier. Blood 2019, 133, 2478-2483. [CrossRef] 
80. Nurden, A.T.; Pillois, X. ITGA2B and ITGB3 gene mutations associated with Glanzmann thrombasthenia. Platelets 2018, 29, 98-101. [CrossRef]

81. Bury, L.; Falcinelli, E.; Chiasserini, D.; Springer, T.A.; Italiano, J.E.; Gresele, P. Cytoskeletal perturbation leads to platelet dysfunction and thrombocytopenia in variant forms of Glanzmann thrombasthenia. Haematologica 2016, 101, 46-56. [CrossRef] [PubMed]

82. Savoia, A.; Kunishima, S.; De Rocco, D.; Zieger, B.; Rand, M.L.; Pujol-Moix, N.; Caliskan, U.; Tokgoz, H.; Pecci, A.; Noris, P.; et al. Spectrum of the mutations in bernard-soulier syndrome. Hum. Mutat. 2014, 35, 1033-1045. [CrossRef]

83. Balduini, C.L.; Savoia, A.; Seri, M. Inherited thrombocytopenias frequently diagnosed in adults. J. Thromb. Haemost. 2013, 11, 1006-1019. [CrossRef] [PubMed]

84. Bottega, R.; Pecci, A.; De Candia, E.; Pujol-Moix, N.; Heller, P.G.; Noris, P.; De Rocco, D.; Podda, G.M.; Glembotsky, A.C.; Cattaneo, M.; et al. Correlation between platelet phenotype and NBEAL2 genotype in patients with congenital thrombocytopenia and $\alpha$-granule deficiency. Haematologica 2013, 98, 868-874. [CrossRef]

85. Kunishima, S.; Nishimura, S.; Suzuki, H.; Imaizumi, M.; Saito, H. TUBB1 mutation disrupting microtubule assembly impairs proplatelet formation and results in congenital macrothrombocytopenia. Eur. J. Haematol. 2014, 92, 276-282. [CrossRef]

86. Kitamura, K.; Okuno, Y.; Yoshida, K.; Sanada, M.; Shiraishi, Y.; Muramatsu, H.; Kobayashi, R.; Furukawa, K.; Miyano, S.; Kojima, S.; et al. Functional characterization of a novel GFI1B mutation causing congenital macrothrombocytopenia. J. Thromb. Haemost. 2016, 14, 1462-1469. [CrossRef] [PubMed]

87. Lex, L.; Wesche, J.; Baschin, M.; Greinacher, A.A.K. Immunofluorescence analysis on a blood smear-Validation of stability of blood smears during storage. Hamostaseologie 2018, 38. [CrossRef]

88. Bender, M.; Stritt, S.; Nurden, P.; Van Eeuwijk, J.M.M.; Zieger, B.; Kentouche, K.; Schulze, H.; Morbach, H.; Stegner, D.; Heinze, K.; et al. Megakaryocyte-specific Profilin1-deficiency alters microtubule stability and causes a Wiskott-Aldrich syndrome-like platelet defect. Nat. Commun. 2014, 5, 4746. [CrossRef]

89. Bain, B.J. Blood Cells: A Practical Guide, 4th ed.; Blackwell Science Ltd.: Oxford, UK, 2006.

90. Noris, P.; Klersy, C.; Gresele, P.; Giona, F.; Giordano, P.; Minuz, P.; Loffredo, G.; Pecci, A.; Melazzini, F.; Civaschi, E.; et al. Platelet size for distinguishing between inherited thrombocytopenias and immune thrombocytopenia: A multicentric, real life study. Br. J. Haematol. 2013, 162, 112-119. [CrossRef]

91. Monteferrario, D.; Bolar, N.A.; Marneth, A.E.; Hebeda, K.M.; Bergevoet, S.M.; Veenstra, H.; Laros-van Gorkom, B.A.P.; MacKenzie, M.A.; Khandanpour, C.; Botezatu, L.; et al. A dominant-negative GFI1B mutation in the gray platelet syndrome. N. Engl. J. Med. 2014, 370, 245-253. [CrossRef]

92. Balduini, C.L.; Pecci, A.; Loffredo, G.; Izzo, P.; Noris, P.; Grosso, M.; Bergamaschi, G.; Rosti, V.; Magrini, U.; Ceresa, I.F.; et al. Effects of the R216Q mutation of GATA-1 on erythropoiesis and megakaryocytopoiesis. Thromb. Haemost. 2004, 91, 129-140.

93. Hatta, K.; Kunishima, S.; Suganuma, H.; Tanaka, N.; Ohkawa, N.; Shimizu, T. A family having type 2B von Willebrand disease with a novel VWF p.R1308S mutation: Detection of characteristic platelet aggregates on peripheral blood smears as the key aspect of diagnosis. Thromb. Res. 2015, 136, 813-817. [CrossRef]

94. Federici, A.B.; Mannucci, P.M.; Castaman, G.; Baronciani, L.; Bucciarelli, P.; Canciani, M.T.; Pecci, A.; Lenting, P.J.; Groot, P.G.D. Clinical and molecular predictors of thrombocytopenia and risk of bleeding in patients with von Willebrand disease type 2B: A cohort study of 67 patients. Blood 2009, 113, 526-534. [CrossRef]

95. Bury, L.; Malara, A.; Momi, S.; Petito, E.; Balduini, A.; Gresele, P. Mechanisms of thrombocytopenia in platelet-type von Willebrand disease. Haematologica 2019, 104, 1473-1481. [CrossRef]

96. Savoia, A.; De Rocco, D.; Panza, E.; Bozzi, V.; Scandellari, R.; Loffredo, G.; Mumford, A.; Heller, P.G.; Noris, P.; De Groot, M.R.; et al. Heavy chain myosin 9-related disease (MYH9-RD): Neutrophil inclusions of myosin-9 as a pathognomonic sign of the disorder. Thromb. Haemost. 2010, 103, 826-832.

97. Millikan, P.D.; Balamohan, S.M.; Raskind, W.H.; Kacena, M.A. Inherited thrombocytopenia due to GATA-1 mutations. Semin. Thromb. Hemost. 2011, 37, 682-689. [CrossRef]

98. Neff, A.T. Sitosterolemia's stomatocytosis and macrothrombocytopenia. Blood 2012, 120, 4283. [CrossRef]

99. Amoruso, M.; Alberio, L.; Nagy, M. EDTA-related degranulation mimicking Storage Pool Disease. Am. J. Hematol. 2018, 93, 1192-1193. [CrossRef] 
100. Kunishima, S.; Matsushita, T.; Kojima, T.; Sako, M.; Kimura, F.; Jo, E.K.; Inoue, C.; Kamiya, T.; Saito, H. Immunofluorescence analysis of neutrophil nonmuscle myosin heavy chain-A in MYH9 disorders: Association of subcellular localization with MYH9 mutations. Lab. Investig. 2003, 83, 115-122. [CrossRef]

101. Kitamura, K.; Yoshida, K.; Shiraishi, Y.; Chiba, K.; Tanaka, H.; Furukawa, K.; Miyano, S.; Ogawa, S.; Kunishima, S. Normal neutrophil myosin IIA localization in an immunofluorescence analysis can rule out MYH9 disorders. J. Thromb. Haemost. 2013, 11, 2071-2073. [CrossRef]

102. Steinberg-Shemer, O.; Tamary, H. Gray platelet syndrome mimicking atypical autoimmune lymphoproliferative syndrome: The key is in the blood smear. Blood 2018, 131, 2737. [CrossRef]

103. Kunishima, S.; Kitamura, K.; Yasutomi, M.; Kobayashi, R. Diagnostic biomarker for ACTN1 macrothrombocytopenia. Blood 2015, 126, 2525-2526. [CrossRef]

104. Antony-Debré, I.; Bluteau, D.; Itzykson, R.; Baccini, V.; Renneville, A.; Boehlen, F.; Morabito, M.; Droin, N.; Deswarte, C.; Chang, Y.; et al. MYH10 protein expression in platelets as a biomarker of RUNX1 and FLI1 alterations. Blood 2012, 120, 2719-2722. [CrossRef]

105. Greinacher, A.; Eekels, J.J.M. Diagnosis of hereditary platelet disorders in the era of next-generation sequencing: "primum non nocere". J. Thromb. Haemost. 2019, 17, 551-554. [CrossRef]

106. ACMG Board of Directors. Points to consider for informed consent for genome/exome sequencing. Genet. Med. 2013, 15, 748-749. [CrossRef]

107. Baschin, M.; Blumentritt, C.; Holzhauer, S.; Karastaneva, A.; Seidel, M.; Greinacher, A. Diagnosis of ETV6-mutation Related Thrombocytopenia by Immunofluorescence Microscopy. Hämostaseologie 2019, 39, SY09-5.

108. Zaninetti, C.; Santini, V.; Tiniakou, M.; Barozzi, S.; Savoia, A.; Pecci, A. Inherited thrombocytopenia caused by ANKRD26 mutations misdiagnosed and treated as myelodysplastic syndrome: Report on two cases. J. Thromb. Haemost. 2017, 15, 2388-2392. [CrossRef]

(C) 2020 by the authors. Licensee MDPI, Basel, Switzerland. This article is an open access article distributed under the terms and conditions of the Creative Commons Attribution (CC BY) license (http://creativecommons.org/licenses/by/4.0/). 